\title{
Does Gamification Improve Flow Experience in Classroom? An Analysis of Gamer Types in Collaborative and Competitive Settings
}

\author{
Alexandre Marinho \\ Instituto de Computação (IC) - \\ Universidade Federal de Alagoas \\ (UFAL) \\ amlf@ic.ufal.br
}

\author{
Ig Ibert Bittencourt \\ Instituto de Computação (IC) - \\ Universidade Federal de Alagoas \\ (UFAL) \\ ig.ibert@ic.ufal.br
}

\author{
Wilk Oliveira dos Santos \\ Instituto de Ciências e Matemática \\ (ICMC) - Universidade de São \\ Paulo (USP) \\ wilk.oliveira@usp.br
}

\author{
Diego Dermeval \\ Faculdade de Medicina (FAMED) - \\ Universidade Federal de Alagoas \\ (UFAL) \\ diego.matos@famed.ufal.br
}

\begin{abstract}
The use of gamification to engage and to motivate people in several environments, including education is notorious in the last years. However, there are different doubts related to the real effects of the application of gamification in educational contexts, mainly associated with the psychological analysis of the effects of gamification, that in some cases highlights that depending of gamification settings, and the students' gamer types and of the gender, it can cause bad effects like students' disengagement or demotivation. At the same time, the flow theory is a psychological theory that defines a mental state of complete control over a person's actions during a task and can be a decisive factor for better increase the engagement and learning of the students. Aiming to investigate whether the students' flow experience changes depending on the gamification configuration and the student's gamer types and gender, we conducted an experiment in a gamified classroom. We analyzed the flow experience of 18 students during four scenarios with different settings of competition and collaboration, comparing their results according to the gamer type and gender. In general, our results did not indicate significant differences in the students' flow experience in the proposed configurations. As a complement, we performed a qualitative study based on the behavioral observations of the experiment that indicated the competition as a stimulating factor of the gamified experience.
\end{abstract}

Keywords: Education; Gamification; Classroom; Gamer type; Collaboration; Competition

Cite as: Marinho, A., Bittencourt, I. I., dos Santos, W. O. \& Dermeval, D. (2019). Does Gamification Improve Flow Experience in Classroom? An Analysis of Gamer Types in Collaborative and Competitive Settings. Brazilian Journal of Computers in Education (Revista Brasileira de Informática na Educação - RBIE), 27(2), 40-68. DOI: 10.5753/RBIE.2019.27.02.40 


\section{Introduction}

Education is a great concern for modern society, and many efforts have been applied to make it both more efficient and available to everyone (Barata et al., 2013). However, the education environment experiences present some problems, one of them being the students' lack of engagement. As there is an association between school dropout and student engagement, both in traditional (Archambault et al., 2009) and on-line (Levy, 2007) scenarios, students' disengagement is a problem to be taken seriously.

In order to solve this problem, several educational environments have been using gamification as a way to keep people more engaged in their activities (Hamari, Koivisto, \& Sarsa, 2014). Gamification relies on game design elements embedded in a learning environment to foster student motivation (Prensky, 2003). This concept has been widely used in education to increase user's engagement and to lead them to enhanced learning (Cheong et al., 2013; Denny, 2013; Domínguez et al., 2013; Goehle, 2013; Landers \& Callan, 2011).

Although it is mostly used in digital environments, face-to-face context can also apply gamification. Lee Sheldon (2011), in his book The Multiplayer Classroom, describes a gamified classroom without the use of technology. Despite the fact that almost no statistical data is provided to confirm the benefits of this approach, some other studies have investigated the use of gamification in the classroom (Hanus \& Fox, 2015; Barata et al., 2013).

Even though widespread, gamification may also be harmful. Recent studies have shown that, depending on the player's profile, some gamification elements may have an opposite effect than expected (Monterrat et al., 2015; Wu \& Chen, 2015). Since then, player type research has gained a new aspect, that is, how to relate known gamer types, to gamification elements in order to ensure better results. For instance, if a student has a profile more interested in competition, he is more likely to enjoy completing missions than collaborating with others. That is one of the grand challenges in gamification research today, how to do gamification based on the player profile (Masthoff \& Vassileva, 2015).

Another possible way of dealing with disengagement is through the use of Flow Theory. The concept of Flow was first introduced by Csikszentmihalyi (1975) as an emotional state that people can feel during specific activities, especially, ones that provide a balance between level of skill and challenge. It is also referred to as the "Optimal Experience" as the person has a genuinely satisfying experience. Since people who experience flow during an activity, are more engaged (D'Mello et al., 2007), we can use this flow experience as a way to engage students either in the classroom or in digital environments.

Knowing that the gamer type can influence the effectiveness of a gamified environment (Masthoff \& Vassileva, 2015), a question arises as to whether they can also change the student flow experience. In this article, we investigated the relationship between the player's profile and the students' flow state during activities performed in a gamified classroom of an undergraduate course.

We conducted the research during four distinct gamified classes, according to the Bartle's gamer types (Bartle, 1996). As a complement to this study, we also analyzed changes in the flow experience between genders according to the gamification settings in the classroom. We conducted an experiment with 18 Brazilian undergraduate students in four different scenarios, mixing elements of competition and collaboration. Each of those students had their player type identified before participating in a quiz-based session. Alongside with the quantitative analysis, we also performed a qualitative analysis, based on the Framework Analysis process, to obtain a broader view of the experiment. In general, our results did not identify significant differences in 
flow experience in any of the gamification settings that were proposed. Still, our results can open space to further questioning in this matter, specially related to the importance of the use of gamification in educational classrooms and about how to better gamify classrooms.

\section{Background}

The following subsections present a background of the central concepts and theories used to base this study, they are: gamification, gamified classrooms, gamer types, and flow theory.

\subsection{Gamification}

Brett Terrill, in a blog post in 2008, described the term "gamification" as "taking game mechanics and applying them to other web properties to increase engagement" (Huotari \& Hamari, 2017). Werbach (2014) defines gamification as "the process of making activities more game-like", and, Deterding et al. (2011) says gamification is the use of game design elements in non-game contexts. Those game elements are smaller pieces used to build a gameplay experience categorized in three types: dynamics ("big picture" aspects of the gamified system), mechanics (basic processes that drive the action forward and generate player engagement) and components (specific instantiations of mechanics and dynamics) (Werbach \& Hunter, 2012).

Gamification has been widely used in education to increase engagement and to lead to enhanced learning outcomes (Domínguez et al., 2013; Landers \& Callan, 2011; Goehle, 2013; Cheong et al., 2013; Denny, 2013). Furthermore, potential benefits of gamification shown by Borges et al. (2013) and Borges et al. (2014) in a systematic mapping applied to education, highlighted uses of gamification for behavioral change, learning improvement, socialization, and engagement.

Khan Academy ${ }^{1}$ is an example of the use of gamification in an educational setting. It is a free online service that allows users to learn about various subjects such as history, math, or economics. As rewards for progress, they receive energy points and badges. Similarly, Codeacademy ${ }^{2}$ teaches students how to code in various programming languages, also using badges and points to track their progress.

However, studies also showed evidence of negative outcomes when using gamification. For instance, Hanus and Fox (2015) showed that some common mechanics often used in a gamified classroom (i.e., competitive context, badges, and leaderboards) might harm some educational outcomes. Furthermore, Monterrat et al. (2015) showed that the player profile towards game-like features might vary from person to person. That means that students have different gamer types, so they are more or less motivated in different ways, depending on their type of player and the used gamification elements (Orji, 2014; Monterrat et al., 2015; Masthoff \& Vassileva, 2015).

\subsubsection{Gamified Classroom}

The use of games in education has a variety of benefits, and several game design mechanics demonstrated success in educational environments (Domínguez et al., 2013). Although associated

\footnotetext{
${ }^{1}$ http://www.khanacademy.org

2 http://www.codecademy.com/
} 
with virtual environments, face-to-face iterations can also apply gamification principles. Employing gamification elements in the classroom could motivate students to learn in new ways or enjoy tasks otherwise considered tedious (Hanus \& Fox, 2015). Also, game design elements commonly used in gamification might be helpful: leaderboards encourage engagement through competition, and badges offer a visual display of progress (Camilleri et al., 2011; Kapp, 2012).

Barata et al. (2013) realized a semester-long study where they added the gamification elements: experience points (XP), levels, leaderboards, challenges and badges to an MSc program, measuring several data like attendance, grades, number of post and downloads. They found that compared with other non-gamified courses, students were more engaged and motivated, although they have admitted that it required more work.

On the other hand, Hanus and Fox (2015) tested students across two courses, one with a gamified curriculum and another without gamification elements, during a 16-week semester. They measured motivation, social comparison, effort, satisfaction, learner empowerment, and academic performance at four points. And found that students in the gamified course showed less motivation, satisfaction, and empowerment over time than those in the non-gamified class.

\subsection{Gamer Type}

Discussion about player types is common in the gaming research community (Hamari \& Tuunanen, 2014; Bateman et al., 2011). A gamer type represents one of the ways that players differ is in their preferred play styles (Orji, 2014), and generally, players have favorites types of games and feel more engaged with some mechanics than others (Monterrat et al., 2015). Bartle (1996) made the first study in this field, proposing a qualitative model of four models obtained through a series of questions to classify the players. Bartle's model has the following types:

- Achiever - interested in doing things to the game, ie. in ACTING on the WORLD.

- Explorer - interested in having the game surprise them, ie. in INTERACTING with the WORLD

- Killer - interested in doing things to people, ie. in ACTING on other PLAYERS.

- Socializer - interested in INTERACTING with other PLAYERS.

Figure 1 illustrates the relationship between the player's preferences. Bartle's gamer type Works as a spectrum so that the player can have characteristics of all types, usually with a dominant model and other secondary ones. 


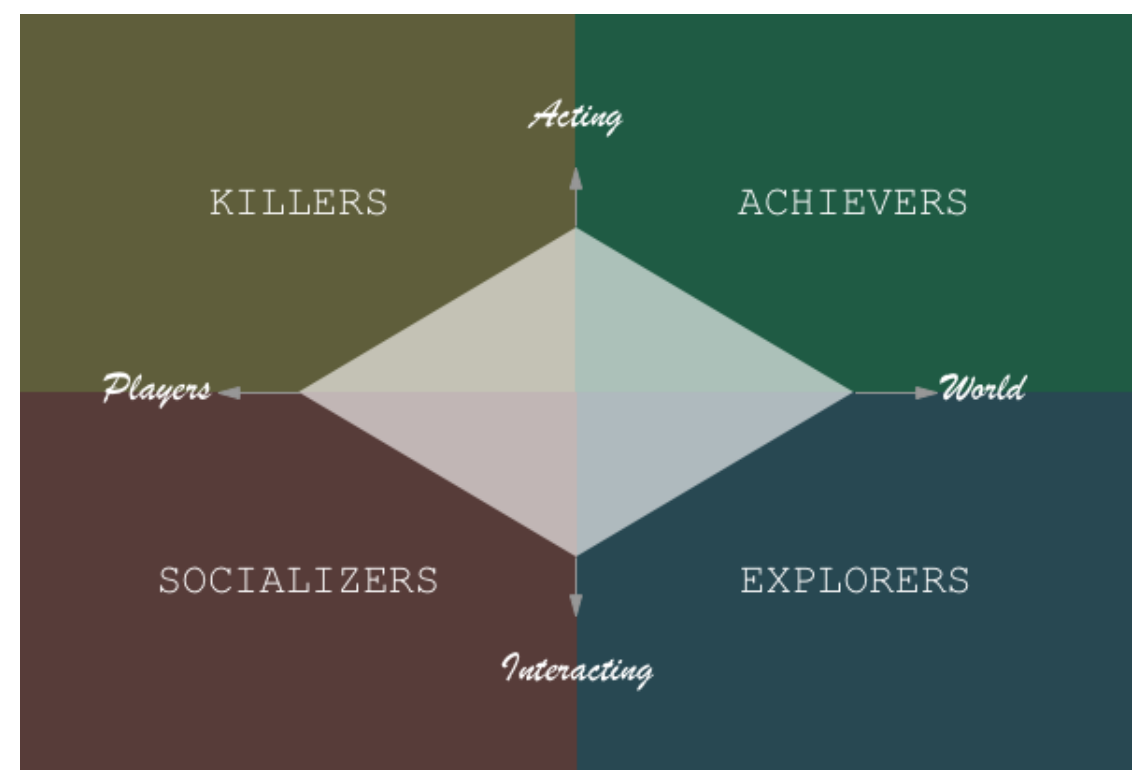

Figure 1 - Bartle's Gamer Type

As Bartle's work refers to MUD players (Multi-user dungeons), other researchers have emerged with the focus on better serving different situations. (Yee et al., 2012; Yee, 2006; Andrade et al., 2016), improved Bartle's proposal by performing a factorial analysis, but still focused on MMORPGs (Massively Multiplayer Online Role-Playing Game). The Demographic Game Design model (DGD1 and DGD2) (Bateman \& Boon, 2005; Bateman et al., 2011) provided insights into player characteristics based on a preexisting psychedelic model (Myers-Briggs typology).

More recently the BrainHex model (Nacke et al., 2011, 2014) categorized players based on insights from neurological findings. BrainHex approach takes inspiration for its archetypes form neurobiological research, previous typology approaches, discussions of patterns of play, and literature on game emotions. This model identifies seven player types, they are: Achiever, Conqueror, Daredevil, Mastermind, Seeker, Socializer and Survivor. Contrary to previous typologies, the BrainHex is not related to a specific game genre like MMORPG (Monterrat et al., 2015). The Bartle's player types are interesting for our study because of its practical simplicity, with profiles that seem plausible for our case, also because of the limited number of students available for the experiment.

\subsection{Flow Theory}

The notion of 'flow' was introduced by Csikszentmihalyi (1975) as a technical term to describe the good feeling or "optimal experience" people have as a motivating factor in their daily activities such as work, sports, and artistic performance (Faiola et al., 2012). Csikszentmihalyi describes flow as an emotional state that people can feel during specific activities, especially, activities that provide a balance between level of skill and challenge. He proposed flow as an emotional state located between anxiety/arousal and relaxation/control (see Figure 2).

Csikszentmihalyi (1991) also proposed the first model to describe flow with the 9 necessary dimensions in order for an activity reach the flow state: (1) clear goals, (2) immediate feedback, (3) balance between challenge and skill, (4) merge of action and awareness, (5) concentration on the task, (6) sense of control, (7) loss of self-consciousness, (8) sense of time changed, (9) "autotelic" experience. Later Hoffman and Novak (1996) summarized those dimensions into five: (1) enjoyment, (2) telepresence, (3) focused attention, (4) engagement, (5) time distortion. More 
recently, Salanova et al. (2014) proposed a simplified model with only three aspects: (1) absorption, (2) enjoyment and (3) intrinsic interest.

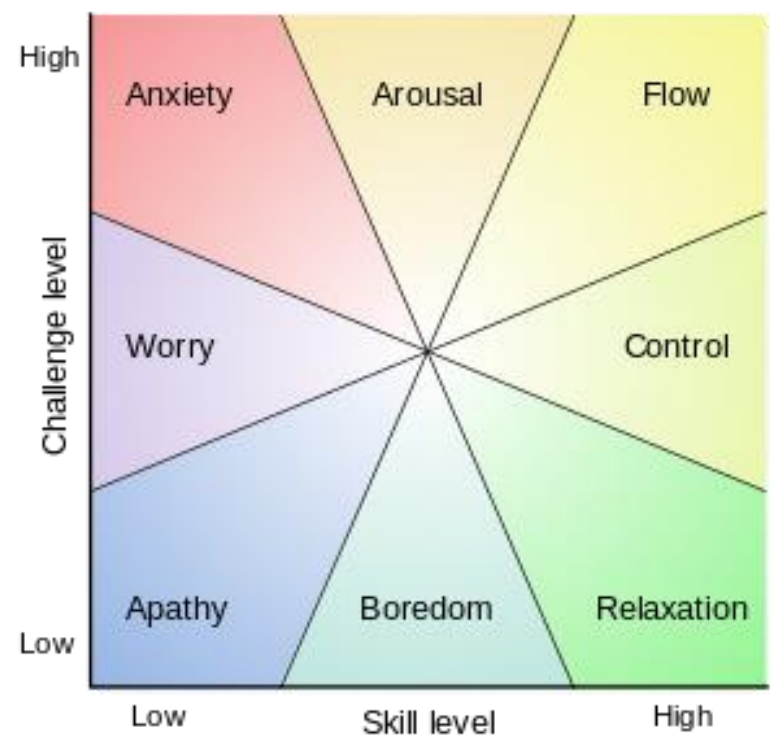

Figure 2 - Flow Model

Several different domains apply flow theory, including sports, human-computer interactions, games, and education. In the education context, Flow has been addressed in several ways, such as, designing learning activities that aid students to achieve the flow state (Kiili et al., 2012) and studies between flow state and an increase in students' learning (Pavlas et al., 2010; Eisenberger et al., 2005). Dos Santos et al., (2018) performed a Systematic Literature Review aiming to identify several aspects of the flow state in the Computers and Education field. They found positive evidence about the benefits of applying Flow Theory in Computers and Education specially in increasing learning and generate satisfaction and enable exploratory behavior.

\subsubsection{Flow Experience Measurement}

In the last decades, a series of methods were developed to identify and measure flow state levels. Jackson and Marsh (1996) first designed the Flow State Scale to examine flow experience in a given situation, while the Dispositional Flow Scale (DFS) (Jackson, Martin, \& Eklund, 2008) assesses the tendency of experiencing flow (Jackson \& Eklund, 2002). Both models were built on the nine dimensions of flow by Csikszentmihalyi (1991). Later, Jackson and Eklund (2002) further refined the models resulting in a new version called DFS-2.

Since then, the DFS-2 scale has been widely applied to the study of several fields, such as, physical activity (González-Cutre et al., 2009; Crust \& Swann, 2013; Gucciardi et al., 2009; Jackson \& Eklund, 2002; Jackson et al., 2008), education (Cermakova et al., 2010), arts (Fritz \& Avsec, 2007; Sinnamon et al., 2012) and digital gaming (Wang et al., 2009; Procci et al., 2012). Also, the DFS-2 was validated by Hamari and Koivisto (2014) in the context of gamification.

Over the years, other researchers developed scales in the educational environment. EGameFlow is composed of 42 items and eight dimensions (Concentration, Clear Goal, Feedback, Challenge, Autonomy (control), Immersion, Social Interaction, Knowledge Improvement) (Fu et al., 2009). Also, (Kiili et al., 2012) proposed a scale by taking into account nine items and ten dimensions (Challenge, Goal, Feedback, Playability, Concentration, Time distortion, Rewarding experience, Loss of self-consciousness, and Sense of control). 
For our study, since we are dealing with a gamified classroom, we choose to use the DFS2 scale. We understand that this scale can give us more reliable results, since several fields continuously utilize it, including education, and already validated it in the gamification environment (Hamari \& Koivisto, 2014).

\section{Study Overview}

The current study investigates the existence and difference of flow experience on players types in a gamified classroom environment according to the gamification settings in the classroom. We selected this scenario based on the mixed results about the effectiveness of gamification (Hamari et al., 2014; Deci, Koestner, \& Ryan, 1999; Hanus \& Fox, 2015), the further studies showing that player profiles also influence the reliability of gamification elements (Monterrat et al., 2015; Masthoff \& Vassileva, 2015; Orji, 2014), and the following pursue of gamified environments tailored for the player preferences. Given the broad range of subjects relating the gamification and gamer types, we focused on finding out if similar behavior also happens for the flow experience in a classroom environment.

Our goal was to design an experiment to detect users' flow experience when performing tasks that mix collaboration and competition in a gamified classroom environment. Therefore, we developed a gamified quiz process applied during four separate classes. The first one had an individual and non-competitive setting, followed by the second with collaboration and noncompetitive environment. By the third class, we introduced competition, initially in an individual setting, and finally a collaborative and competitive setting for the fourth class. At the end of every session, each student answered a questionnaire to determine their flow experience. Figure 3 depicts an overview of the experiment.

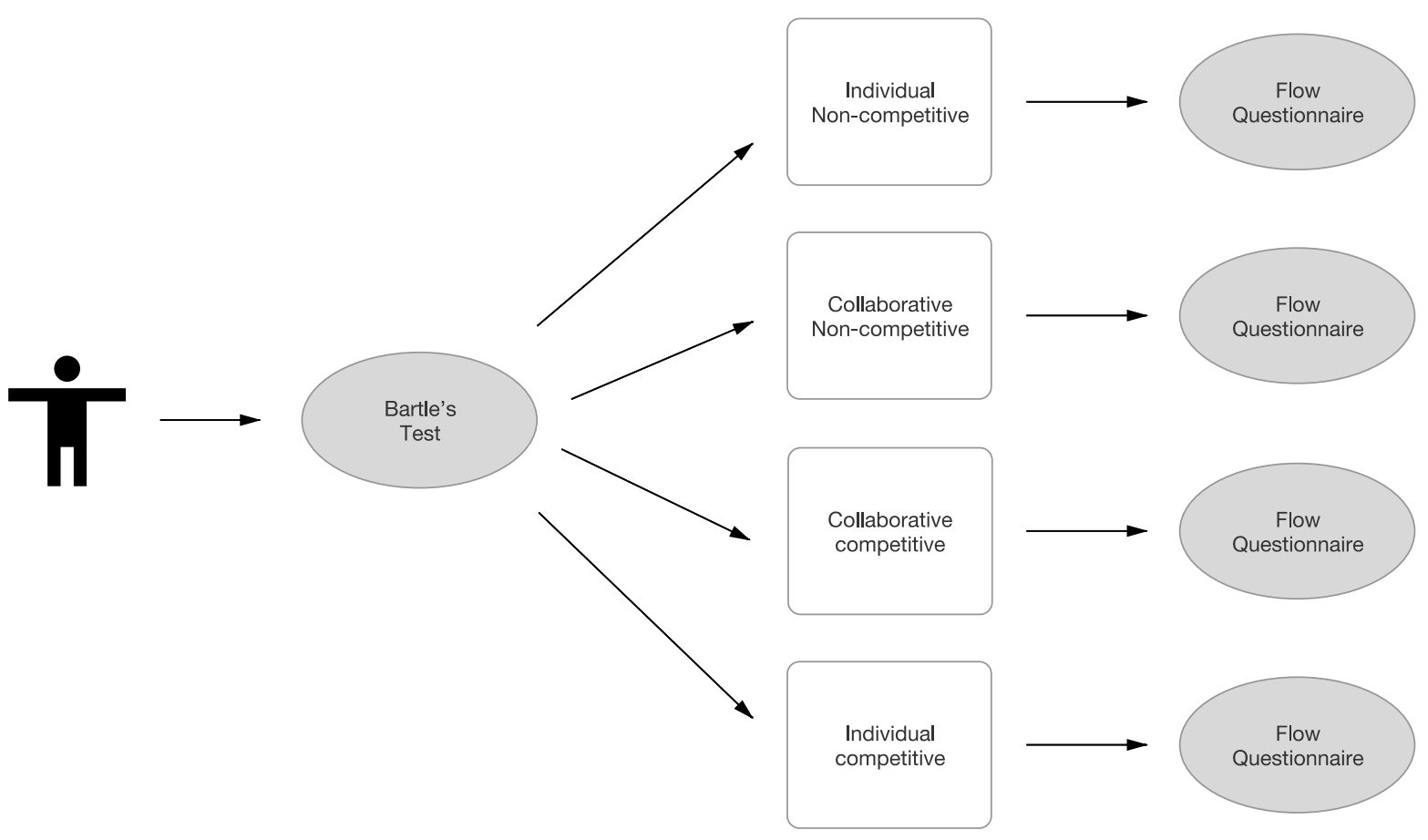

Figure 3 - Study overview 


\section{Experiment}

This section aims to present our design of experiment to measure the students' flow experience in the different gamification settings according to their gamer types and gender.

\subsection{Design}

The Experiment Design has the objective of describing or explaining the information variation under hypothetical conditions to reflect such variation. The term is generally associated with true experiments in which the design introduces conditions that directly affect the information variation. In this study, the Goal Question Metric (GQM) (Basili et al., 1994) approach is adopted.

The Goal/Question/Metric (GQM) (Basili et al., 1994; Briand et al., 1996; Solingen \& Berghout, 1999) method assumes that for an organization to measure in an accurate way it must:

- Specify the goals for itself and its projects;

- Trace those goals to the data that is intended to define those goals operationally; and

- Provide a framework for interpreting the data regarding the goals that were established.

The result of the application of the GQM method is the specification of a measurement model targeting a particular set of issues and rules for the interpretation of the measured data (Wohlin et al., 2012). The resulting measurement model has three levels, as illustrated by the hierarchical structure in Figure 4:

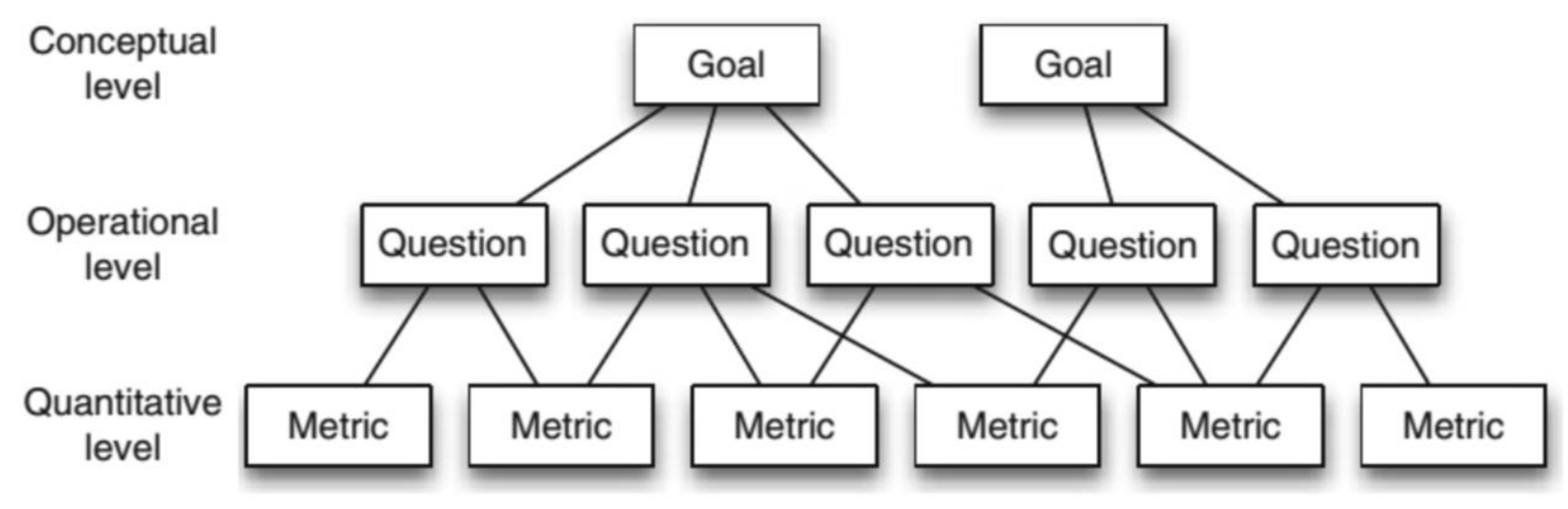

Figure 4 - GQM model structure.

- Conceptual level (Goal): A goal is defined for an object, for a variety of reasons, regarding the several models of quality, from different points of view, related to a specific environment. The objects of measurement are: products, processes, and resources (Wohlin et al., 2012).

- Operational level (Question): A set of questions is used to characterize the way the assessment/achievement of a specific goal is going to be performed based on some characterization model. Questions try to characterize the measurement objects (product, process, and resource) regarding the selected quality aspect and to determine its quality from the selected point of view (Wohlin et al., 2012).

- Quantitative level (Metric): A set of data is associated with every question to answer it in a quantitative way (either objectively or subjectively) (Wohlin et al., 2012). 
The process of setting goals is critical to the successful application of the GQM method. Goals are formulated based on (1) policies and strategies of the organization, (2) descriptions of processes and products, and (3) organization models. When goals are formulated, questions are developed based on these goals. Once the questions have been developed, we proceed to associate the questions with the appropriate metrics (Wohlin et al., 2012).

\subsection{Participants}

Combining the data collected in the four days that the experiment happened, we obtained information from a total of 18 Brazilian undergraduate students ( 8 males and 10 females). All the subjects were enrolled in the Design course of Tiradentes University, attending the discipline of Constructive Details and Lighting. After applying Bartle's test and finding out which type of player each participant had, we obtained the following result: 2 Achiever (9\%), 4 Socializer $(18 \%), 3$ Killer (14\%) and 12 Explorer (59\%), a total of 21 because some students were classified with more than one type.

\subsection{Goals}

The main goal of this experiment is to evaluate students' flow experience based on their gamer types in four different scenarios. The specific goals are presented as it follows:

- Measure students' flow experience in an individual non-competitive classroom;

- Measure students' flow experience in a collaborative non-competitive classroom;

- Measure students' flow experience in an individual competitive classroom;

- Measure students' flow experience in a collaborative competitive classroom;

\subsection{Research Questions and Hypothesis}

In this section we present the research questions and hypothesis for the quantitative analysis we performed.

\subsubsection{Gamer Type}

RQ1. Is there a significant difference in flow experience between gamer types in an individual non-competitive activity?

H1.0 - There is no difference in the flow experience between the player types in an individual non-competitive activity.

H1.1 - There is difference in the flow experience between the player types in an individual non-competitive activity.

RQ2. Is there a significant difference in flow experience between gamer types in a collaborative non-competitive activity?

H2.0 - There is no difference in the flow experience between the player types in a noncompetitive collaborative activity.

H2.1 - There is difference in the flow experience between the player types in a noncompetitive collaborative activity.

RQ3. Is there a significant difference in flow experience between gamer types in an individual competitive activity? 
H3.0 - There is no difference in the flow experience between the player types in an individual competitive activity.

H3.1 - There is difference in the flow experience between the player types in an individual competitive activity.

RQ4. Is there a significant difference in flow experience between gamer types in a collaborative competitive activity?

H4.0 - There is no difference in the flow experience between the player types in a collaborative competitive activity.

H4.1 - There is difference in the flow experience between the player types in a collaborative competitive activity.

\subsubsection{Gender}

RQ5. Is there significant difference in flow experience between gender in an individual noncompetitive activity?

H5.0 There is no difference in the flow experience between genders in an individual noncompetitive activity.

H5.1 There is difference in the flow experience between genders in an individual noncompetitive activity.

RQ6. Is there significant difference in flow experience between gender in a collaborative noncompetitive activity?

H6.0 There is no difference in the flow experience between genders in a collaborative noncompetitive activity.

H6.1 There is difference in the flow experience between genders in a collaborative noncompetitive activity.

RQ7. Is there significant difference in flow experience between gender in an individual competitive activity?

H7.0 There is no difference in the flow experience between genders in an individual competitive activity.

H7.1 There is difference in the flow experience between genders in an individual competitive activity.

RQ8. Is there significant difference in flow experience between gender in a collaborative competitive activity?

H8.0 There is no difference in the flow experience between genders in a collaborative competitive activity.

H8.1 There is difference in the flow experience between genders in a collaborative competitive activity.

\subsection{Method}

The method of our study is characterized as a quantitative and qualitative study. We used empirical tools for instance in order to identify the student's gamer type and the students' flow experience, however, we also qualitatively analyzed our data to provide a deeper discussion. 


\subsubsection{Gamer Type Assessment}

As presented in Figure 3, participants had their gamer type defined before any of the classes took place. Their player type was measured by applying a Portuguese version of the Bartle test, proposed by (Andreasen \& Downey, 2002). The test was composed of 30 questions with two possible answers, each associated with one particular profile. In order to calculate, we sum the number of responses related to each gamer type, resulting in values for all four, the highest one being the primary gamer type. For some of the subjects, more than one primary profile was detected, so each profile was treated as a different person.

\subsubsection{Flow Experience Assessment}

At the end of each class we measured the level of flow experience in each participant, we obtained this measure applying a Portuguese version of the DFS-2 questionnaire. The test is composed of 36 statement items. Each statement had an answer based on a five-point Likert scale varying from "strongly disagree" to "strongly agree" where "strongly disagree" answer equals one point and "strongly agree" answer accounted five points. Each of those statements was related to a specific flow dimension and in order calculate values of each one we added the points and calculated the mean. As a result, we had a value for each flow experience structure individually, Challenge-Skill Balance (CS), Merging Action \& Awareness (AA), Clear Goals (CG), Feedback (FB), Concentration (CT), Control (CO), Loss of Self Consciousness (LS), Time transformation (TI) and Autotelic experience (AU).

\subsection{Procedures and Materials}

The participants were asked to give their consent to take part in the study. Afterwards, they participated in four classes, each one composed of two main activities, a gamified quiz, and a flow experience questionnaire. Each class happened on a different day and had a limited time of 100 minutes to finish both activities. The flow experience assessment was executed at the end of each class and consisted of a 36-question questionnaire that asked participants about their impressions during the quiz. Each day had its particular setting, combining elements of competition and collaboration. On the following sections, we describe general and specific characteristics of each proposed class.

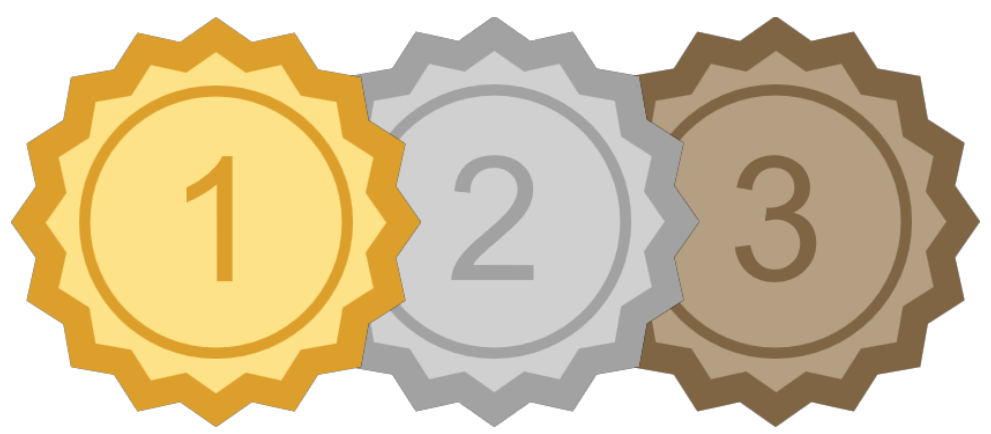

Figure 5 - Medals 


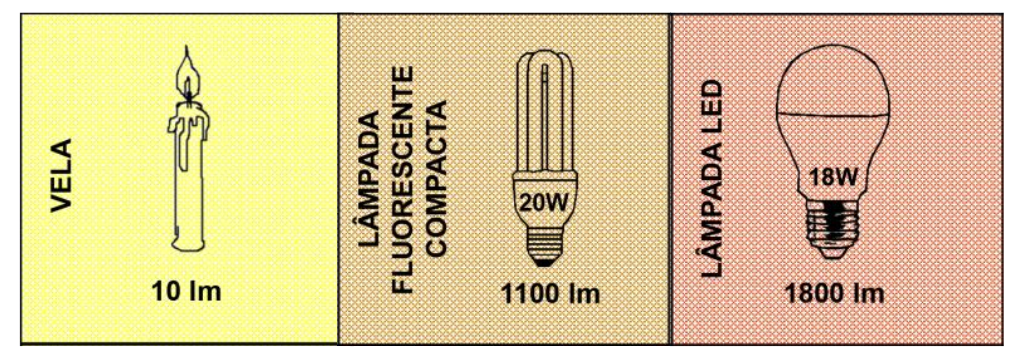

Figure 6 - Tokens

\subsubsection{General Rules}

During the experiment, there were shared elements among all classes, mainly about gamification aspects. (i) All activities consisted of answering questions about contents previously addressed in class, all of those questions had multiple choice answers. (ii) Each session had three rounds of questioning, with rising difficulty (easy, medium and hard). Each round consisted of three questions of the same level, a total of nine for each class. Each question had a maximum resolution time of five minutes. (iii) The experiment was conducted by the subject's teacher and questions were presented to participants through a projection screen. (iv) At every correct answer, the teacher provided physical tokens (Figure 6) and medals (Figure 5), even though each class had its own rule for distributing them. (v) For every day, there were varied forms of performance-based rewards.

\subsubsection{Class One - Individual, non-competitive (NCIA)}

For this class, students were working individually and without competition. For each correct answer, they received a token as a representation of their success, at the end of each round, medals were given based on how many tokens the student had. A bronze medal for one token, silver medal for two and gold medal for three. In exchange for the tokens, they received rewards (candy). First-round tokens were worth one piece of candy, second round two pieces and third round three pieces. There was also a surprise prize, rewarding more pieces of candy to those who had a specific combination of medals.

\subsubsection{Class Two - Collaborative, non-competitive (NCCA)}

In the second class, students worked in solving questions collaboratively. Before the beginning of the class, we randomly assigned groups of three students. For this experiment, competition was also not stimulated. Once again, tokens were given for every correct answer, except, this time, tokens belonged to the group, since they were working together, the same rule applied to medals. In the end, they received candy according to their tokens: First round tokens were worth three pieces of candy, second round six pieces and third round nine pieces.

\subsubsection{Class Three - Individual, competitive (CIA)}

During this session, we introduced the concept of competition for the first time, stimulating the game through the use of a raking system. We displayed the ranking for everyone at the end of every round, indicating the score of each student. Once again, they received tokens for every correct answer, the difference this time was that they also valued points. Tokens of the three rounds were worth respectively 5,8 and 13 points. The medals reflected how quickly they answered the questions. The student with the first correct answer received a small piece of candy, and at the end, only the three best-placed students won prizes.

\subsubsection{Class Four - Collaborative, competitive (CCA)}


The last session also stimulated competition, except this time, between groups. Once again groups were randomly assigned at the beginning. Tokens had the same values for points $(5,8$ and 13 respectively); and medals were given based on how quickly they answered. This time, the raking system indicated the performance of each group. The group with the first correct answer received a small piece of candy for each member and, in the end, only the three best-placed teams won the prizes.

After running the experiment, we generated descriptive statistics and ran normality checks to help us decide which type of hypothesis test was the best fit to our data. Afterwards, we tested flow experience hypotheses considering a confidence interval of $95 \%$.

\section{Results}

This section aims to present the results of our study. How we analyzed different constructs in different settings, in order to facilitate the organization and understanding of our results, we organized the results into different subsections.

\subsection{Quantitative Analysis}

\subsubsection{Descriptive Data}

The data collected during the experiment is summarized in the Tables 1 and 2. Table 1 represents data for the plyer type analysis, and Table 2 represents the data for gender analysis. Based on these data, we decided not to perform statistical analysis for player types because of a very limited sample of subjects in each type. This limitation makes it impossible to perform the statistical tests because it does not meet the needs to complete it. However, for the gender analysis, we decided to use parametric hypothesis tests.

Table 1 - Descriptive data for player type analysis.

\begin{tabular}{|l|l|c|c|}
\hline \multicolumn{1}{|c|}{ Scenario } & Player type & $\mathrm{N}$ & Mean \\
\hline NCIA & Explorer & 10 & 3.563 \\
\hline NCIA & Achiever & 1 & 3.701 \\
\hline NCIA & Socializer & 4 & 3.944 \\
\hline NCIA & Killer & 3 & 3.28 \\
\hline NCCA & Explorer & 9 & 3.598 \\
\hline NCCA & Achiever & 2 & 3.592 \\
\hline NCCA & Socializer & 3 & 3.805 \\
\hline NCCA & Killer & 2 & 3.388 \\
\hline CIA & Explorer & 11 & 3.921 \\
\hline CIA & Achiever & 1 & 3.013 \\
\hline CIA & Socializer & 2 & 4 \\
\hline CIA & Killer & 2 & 3.597 \\
\hline CCA & Explorer & 9 & 3.953 \\
\hline
\end{tabular}




\begin{tabular}{|l|l|l|l|}
\hline CCA & Achiever & 2 & 3.601 \\
\hline CCA & Socializer & 3 & 4.083 \\
\hline CCA & Killer & 2 & 3.236 \\
\hline
\end{tabular}

Table 2 - Descriptive data for gender analysis.

\begin{tabular}{|l|c|c|c|c|c|}
\hline \multicolumn{1}{|c|}{ Scenario } & Gender & Mean & SD & N & Shap \\
\hline NCIA & F & 3.634 & 0.556 & 6 & 0.139 \\
\hline NCIA & M & 3.580 & 0.502 & 8 & 0.253 \\
\hline NCCA & F & 3.401 & 0.422 & 7 & 0.968 \\
\hline NCCA & M & 3.917 & 0.445 & 5 & 0.834 \\
\hline CCA & F & 3.917 & 0.469 & 7 & 0.193 \\
\hline CCA & M & 3.722 & 0.755 & 7 & 0.926 \\
\hline CIA & F & 3.771 & 0.888 & 8 & 0.992 \\
\hline CIA & $\mathrm{M}$ & 3.699 & 0.795 & 6 & 0.667 \\
\hline
\end{tabular}

\subsubsection{Flow Experience by Gamer Type}

For the player type test, after analyzing the descriptive data obtained, we noticed that the available sample was not distributed satisfactorily among the study groups. Thus, our data were not enough to perform the necessary statistical tests, making it impossible to perform the desired test. However, we decided to conduct a test by comparing the proposed gamification settings with the type of player which obtained the highest number of students. The Explorer type was analyzed against the combination of collaboration and competition.

To accomplish that, we used the One-Way Analysis of Variance over participants flow experience in all four scenarios. As Table 3 shows, as the p-value (0.366) is greater than the level of significance $(0.05)$ we failed to detect any differences between any of the proposed settings. That means, the collected evidence shows no indication of different flow experience in any of the proposed scenarios. This result was confirmed running the Tukey method, as a post-hoc test, to compare the means between settings (Table 4).

Table 3 - One-Way ANOVA for Explorer type.

\begin{tabular}{|c|c|c|c|c|c|}
\hline Cases & $\begin{array}{c}\text { Sum of } \\
\text { Squares }\end{array}$ & $\mathrm{df}$ & $\begin{array}{c}\text { Mean } \\
\text { Square }\end{array}$ & $\mathrm{F}$ & $\mathrm{p}$ \\
\hline scenario & 1.244 & 3 & 0.415 & 1.091 & $\mathbf{0 . 3 6 6}$ \\
\hline Residual & 13.296 & 35 & 0.380 & & \\
\hline
\end{tabular}

Table 4 - Table 4: Tukey method results.

\begin{tabular}{|l|l|c|c|c|c|}
\hline Scenario A & Scenario B & $\begin{array}{c}\text { Mean } \\
\text { Difference }\end{array}$ & SE & $\mathrm{t}$ & $\mathrm{p}$ tukey \\
\hline CCA & CIA & 0.032 & 0.277 & 0.115 & $\mathbf{0 . 9 9 9}$ \\
\hline CCA & NCCA & 0.355 & 0.291 & 1.222 & $\mathbf{0 . 6 1 7}$ \\
\hline CCA & NCIA & 0.390 & 0.283 & 1.376 & $\mathbf{0 . 5 2 2}$ \\
\hline
\end{tabular}




\begin{tabular}{|l|l|l|l|l|l|}
\hline CIA & NCCA & 0.323 & 0.277 & 1.166 & $\mathbf{0 . 6 5 2}$ \\
\hline CIA & NCIA & 0.358 & 0.269 & 1.329 & $\mathbf{0 . 5 5 1}$ \\
\hline NCCA & NCIA & 0.035 & 0.283 & 0.123 & $\mathbf{0 . 9 9 9}$ \\
\hline
\end{tabular}

\subsubsection{Flow Experience by Gender}

For the gender analysis, we choose to use t-test to compare the flow experience on males and females in the four gamification settings. As Table 3 shows, all p-values are greater than the level of significance (0.05), meaning we failed to reject the null hypothesis. According to the collected data, there were no significant difference in participants' flow experience.

Table 5 - Results for gender analysis

\begin{tabular}{|c|l|c|c|c|}
\hline Hypothesis & Scenario & Effect Size & $\mathrm{p}$-value & Result \\
\hline H5 & NCIA & 0.104 & 0.851 & Failed to reject \\
\hline H6 & NCCA & -1.196 & 0.068 & Failed to reject \\
\hline H7 & CCA & 0.084 & 0.878 & Failed to reject \\
\hline H8 & CIA & 0.309 & 0.573 & Failed to reject \\
\hline
\end{tabular}

\subsection{Qualitative Analysis}

During the same experiment, we made a series of observations with the objective of creating a qualitative analysis to better understand the investigated scenario and complement the presented results. To accomplish that, we used a process called Framework Analysis, it is an analytical process, involving a distinct number of highly interconnected steps. Also, it involves a systematic process of filtering, mapping and classifying the material according to the main issues and themes (Ritchie \& Spencer, 2002). Framework Analysis has five fundamental steps: (1) Familiarization, (2) Identifying a thematic framework, (3) Indexing, (4) Charting and (5) Mapping and interpretation.

\subsubsection{Familiarization}

Throughout four classes in October and November 2017, an empirical study was carried out in a technological education environment, inside a 2nd period class of Interior Design course in the University Center Tiradentes (UNIT / AL). We executed the experiment in the discipline called Constructive Details and Lighting. This course had 80 hours of workload with two weekly meetings. The group used in the analysis had a total of 18 students enrolled.

Before the experiment, students answered the Bartle questionnaire, consisting of 30 questions to determine the player profile among four possible options, Achiever, Socializer, Killer and Explorer. Section 4.2 presented the results for this test, showing a large number of Explorer type participants. The students performed gamified classroom activities during the experiment, within the context of lighting concepts. Students received physical tokens, medals, and prizes based on their performance as rewards for answering multiple-choice questions. At each session, a different format was applied, mixing different activity aspects such as individual/collaborative and competitive/non-competitive. 


\subsubsection{Identifying a Thematic Framework}

To identify the themes for our framework, we used the combination of common gamification mechanics, such as competition and collaboration. We present these combinations in Table 6 as our themes.

Table 6 - Identified themes.

\begin{tabular}{|l|}
\hline \multicolumn{1}{|c|}{ Themes } \\
\hline T1. Individual, non-competitive classroom \\
\hline T2. Collaborative, non-competitive class \\
\hline T3. Individual, competitive class \\
\hline T4. Collaborative, competitive class \\
\hline
\end{tabular}

\subsubsection{Indexing}

Here we list our categorized findings for each of the themes showed in the previous section. Categories are Gamification for observations related to elements of gamification and Pedagogical for findings related to pedagogy. Table 7 presents these findings.

Table 7 - Index of our findings

\begin{tabular}{|l|l|l|l|}
\hline \multicolumn{2}{|c|}{ Individual, non-competitive } & \multicolumn{2}{c|}{ Individual, Competitive } \\
\hline Findings & Categories & Findings & Categories \\
\hline $\begin{array}{l}\text { 1.1 Many students } \\
\text { answered easy level } \\
\text { questions, however they } \\
\text { did not perform well in } \\
\text { median and hard levels. }\end{array}$ & Pedagogical (C1) & $\begin{array}{l}\text { 3.1 We observed that some } \\
\text { students went on-line to } \\
\text { search for answers. }\end{array}$ & $\begin{array}{l}\text { Pedagogical } \\
\text { (C1) }\end{array}$ \\
\hline $\begin{array}{l}\text { 1.2 We noticed, a few } \\
\text { moments during the } \\
\text { experiment, some } \\
\text { students shared answers } \\
\text { with each other. }\end{array}$ & Pedagogical (C1) & $\begin{array}{l}\text { 3.2 Great excitement } \\
\text { happened amongst students } \\
\text { to be the first one to answer. }\end{array}$ & $\begin{array}{l}\text { Gamification } \\
\text { (C2) }\end{array}$ \\
\hline $\begin{array}{l}\text { 1.3 Almost everyone } \\
\text { complained about the } \\
\text { difficulty of levels } \\
\text { medium and hard. }\end{array}$ & $\begin{array}{l}\text { Pedagogical (C1), } \\
\text { Gamification (C2) }\end{array}$ & $\begin{array}{l}\text { 3.3 Several quick answers } \\
\text { led to errors in easy } \\
\text { questions. }\end{array}$ & $\begin{array}{l}\text { Gamification } \\
\text { (C2) }\end{array}$ \\
\hline $\begin{array}{l}\text { 1.4 Giving rewards at } \\
\text { each round was a } \\
\text { stimulating factor to } \\
\text { answer more questions. }\end{array}$ & Gamification (C2) & $\begin{array}{l}\mathbf{3 . 4} \text { There was great } \\
\text { anticipation to reveal the } \\
\text { rank at the end of each } \\
\text { round. }\end{array}$ & $\begin{array}{l}\text { Gamification } \\
\text { (C2) }\end{array}$ \\
\hline $\begin{array}{l}\text { 1.5 Students used up all } \\
\text { available time to answer } \\
\text { each question. }\end{array}$ & Gamification (C2) & \multicolumn{1}{c|}{ Collaborative, competitive } \\
\hline \multicolumn{1}{|c|}{ Collaborative, non-competitive } & & \\
\hline
\end{tabular}




\begin{tabular}{|l|l|l|l|}
\hline Findings & Categories & Findings & Categories \\
\hline $\begin{array}{l}\text { 2.1 We observed that, } \\
\text { although it was a } \\
\text { collaborative activity, } \\
\text { students' performance } \\
\text { was similar to previous } \\
\text { class. That is, they } \\
\text { answered more easy } \\
\text { level questions than } \\
\text { others. }\end{array}$ & Pedagogical (C1) & $\begin{array}{l}\text { 4.1 During this class, } \\
\text { overall performance of } \\
\text { groups was notably better } \\
\text { than previous classes. In } \\
\text { fact, several groups were } \\
\text { tied in the first position } \\
\text { almost to the end. }\end{array}$ & $\begin{array}{l}\text { Pedagogical } \\
\text { (C1) }\end{array}$ \\
\hline $\begin{array}{l}\text { 2.2 Once again there } \\
\text { were complaints about } \\
\text { time to solve the } \\
\text { questions and their } \\
\text { difficulty, however less } \\
\text { than previous class. }\end{array}$ & $\begin{array}{l}\text { Pedagogical (C1), } \\
\text { Gamification (C2) }\end{array}$ & $\begin{array}{l}\text { 4.2 We noticed great } \\
\text { excitement from all groups } \\
\text { in getting things done } \\
\text { quickly. }\end{array}$ & $\begin{array}{l}\text { Gamification } \\
\text { (C2) }\end{array}$ \\
\hline $\begin{array}{l}\text { 2.3 Excitement about } \\
\text { the class diminished in } \\
\text { comparison to previous } \\
\text { class. }\end{array}$ & Gamification (C2) & $\begin{array}{l}\text { 4.3 During this class, groups } \\
\text { finished answering } \\
\text { questions faster than } \\
\text { maximum time available. }\end{array}$ & $\begin{array}{l}\text { Gamification } \\
\text { (C2) }\end{array}$ \\
\hline $\begin{array}{l}\text { 2.4 Once again, students } \\
\text { used up all available } \\
\text { time to answer each } \\
\text { question. }\end{array}$ & Gamification (C2) & & \\
\hline
\end{tabular}

\subsubsection{Charting}

Table 8 presents a summarized matrix of our findings, and their respective categories showed in the indexing phase.

Table 8 - Summarized matrix of our findings.

\begin{tabular}{|l|c|c|c|c|c|c|c|c|}
\hline & \multicolumn{4}{|c|}{ Pedagogy (C1) } & \multicolumn{4}{c|}{ Gamification (C2) } \\
\hline & $\mathrm{T} 1$ & $\mathrm{~T} 2$ & $\mathrm{~T} 3$ & $\mathrm{~T} 4$ & $\mathrm{~T} 1$ & $\mathrm{~T} 2$ & $\mathrm{~T} 3$ & $\mathrm{~T} 4$ \\
\hline Complaints about time to answer & $\mathrm{X}$ & $\mathrm{X}$ & & & $\mathrm{X}$ & $\mathrm{X}$ & & \\
\hline Low performance & $\mathrm{X}$ & $\mathrm{X}$ & & & & & & \\
\hline Good performance & & & & $\mathrm{X}$ & & & & \\
\hline Sharing answers & $\mathrm{X}$ & & $\mathrm{X}$ & & & & & \\
\hline Giving rewards & & & & & $\mathrm{X}$ & $\mathrm{X}$ & $\mathrm{X}$ & $\mathrm{X}$ \\
\hline Fast answers & & & $\mathrm{X}$ & $\mathrm{X}$ & & & & \\
\hline Competition (rank) & & & & & & & $\mathrm{X}$ & $\mathrm{X}$ \\
\hline
\end{tabular}

\subsubsection{Mapping and Interpretation}


In this final step, we comment on the results of our observations that were indexed, categorized and finally summarized.

The first finding we can comment is about the students' complaints about time to answer $(1.3,2.2)$. That can be explained by students not being prepared for more difficult questions. This matches our second finding of low performance $(\mathbf{1 . 1}, \mathbf{2 . 1})$ in higher levels. Perhaps students did not dedicate enough time to study the subject, or even, needed more questions to evolve to next level.

An interesting finding is that good performance (4.1) happened alongside with competition (3.2, 3.4, 4.2). That may be an indication that the competition factor stimulated students' engagement to perform better than usual (according to the teacher). Another interesting finding was that competition matched fast answers $(3.2,3.3,3.2,4.3)$ which also caused a few wrong answers, maybe in a rush to answer and receive a reward. Also, we were surprised, that competition made a significant difference in students' participation, given that most of them did not classify as a competition profile (Killer). Instead, the vast majority was classified with exploration characteristics (Explorer).

We also noticed students sharing answers $(1.2,3.3)$ either with each other or online. That may be an indication of the lack of commitment to the subject, or even, their eagerness to win. Lastly, giving rewards $(1.4,3.3,4.2)$ even though simple, definitely excite students to win. That gives us the idea that, of those classes, the competition factor was the one that gave more benefits to the class.

\section{Discussion}

Given the results presented previously, in the experiment about the participants' flow experience by type of player, it was not possible to obtain enough data that would allow to carry out the analysis. However, we selected the most found profile among the participants (Explorer), to perform an additional test, where we analyzed the existence of differences in the flow experience in the proposed gamification configurations. Results showed no indication of differences for the Explorer type in any of the combinations of competition and collaboration. Future work may yield better results if a more significant sample of the population can be evaluated.

The tests evaluating participants' flow experience by gender, also did not present enough evidence to detect any significant difference between male and female subjects. Murcia et al., 2008 obtained similar results in their research in the area of sports, this may indicate that the gender has no significant influence on the flow experience. Perhaps the state of flow is such an experience that both men and women have the same disposition to attain it. Factors that influence gamified educational environments, such as stereotype threat (Albuquerque et al., 2017), could also have an impact in those male/female interactions. Further research on this subject is desired to further elucidate the differences in the flow experience between men and women. There is still a wide field of research on gender in relation to flow, along with various configurations of gamification

In our qualitative analysis, we addressed one point, the fact that competition made an impact on the students' behavior, considering that they were more excited during competition settings than other ones. That alone would not be so attractive, except that most of the students in this scenario were classified with the dominant profile of Explorer, which has no competition characteristics. This fact leads us to some assumptions of why this happened, maybe the Bartle 
test failed to identify profiles accurately, or even, competition was part of a secondary type for those students. We can pursue that question in future works related to player profile.

We highlighted that our study has limitations, especially regarding the statistical tests, but we also believe that this is our first step into this field. As our sample for each class was small, all of our tests may have been compromised. On the other hand, we feel that this area of research still needs to be more investigated. We are compromised to follow this path, using the principles proposed by Bittencourt and Isotani (2018) as guideline to our future works. Some different situations to examine are: doing the same study with a more significant sample for better statistical power; using gamification in a digital environment, analyzing other gamer types (i.e., BrainHex, Hexhad) and others.

\section{Threats to Validity}

For this experiment, we can identify the existence of some threats to validity. To organize this section, we classified the threats using the Internal, External, Construct and Conclusion categories (Wohlin et al., 2012).

Internal: Since we are experimenting on humans, we are prone to internal threats, such as: (i) history - It is possible that the moment the test happened may have affected the results; (ii) maturation - as the experiment occurred during a whole class (approximately 50 minutes) and this experience happened during four sessions, it is possible that the students were bored in answering the evaluation questionnaire; (iii) positive bias - as DFS-2 questionnaire has answers based on the Likert scale, participants may tend to choose more positive options.

External: The participants of the experiment represent only the academic context. As mentioned earlier, the participants were single-class higher education students. In this way, we cannot expand the results of this experiment to other circumstances.

Construct: This experiment measures many different items from different aspects, and the questions may not measure some constructs. To minimize these threats, we selected methodologies and instruments empirically validated and commonly used in the scientific empirical studies from the community.

Conclusion: The size of the available sample (18 students) is also a threat to the validity of the experiment. The low number of students meant that the groups evaluated had many different sizes and in some cases were insufficient to perform the statistical analyzes.

\section{Concluding Remarks}

In this study, a group of students had their player type identified using a Portuguese version of the Bartle test, then participated in an experiment that consisted of four gamified classes: (i) individual, non-competitive; (ii) collaborative, non-competitive; (iii) individual, competitive and (iv) collaborative, competitive. Each participant answered a DFS-2 questionnaire at the end of each class to assess their flow experience. We tested hypotheses regarding participants' flow experience regarding their gamer type and participants' flow experience based on gender. Results suggest that there were no differences in both situations. On the other hand, there are still several questions we can evaluate in future studies. 


\section{References}

Albuquerque, J., Bittencourt, I., Coelho, J., \& Silva, A. (2017). Does gender stereotype threat in gamified educational environments cause anxiety? An experimental study. Computers \& Education, 115, 161-170. doi: 10.1016/j.compedu.2017.08.005 [GS Search].

Andrade, F., Marques, L., Bittencourt, I., \& Isotani, S. (2016) QPJ-BR: Questionário para Identificação de Perfis de Jogadores para o Português-Brasileiro. V Congresso Brasileiro de Informática na Educação. doi: 10.5753/cbie.sbie.2016.637 [GS Search]

Andreasen, E., \& Downey, B. (2002). The mud companion - the premier printed mud magazine. Retrieved from http://archive.is/w5UdT.

Archambault, I., Janosz, M., Fallu, J.-S., \& Pagani, L. S. (2009). Student engagement and its relationship with early high school dropout. Journal of Adolescence, 32(3), 651-670. doi: j.adolescence.2008.06.007 [GS Search].

Barata, G., Gama, S., Jorge, J., \& Goncalves, D. (2013). Engaging Engineering Students with Gamification. 2013 5th International Conference on Games and Virtual Worlds for Serious Applications (VS-GAMES)(January), 1-8. doi: 10.1109/VS-GAMES.2013.6624228 [GS Search].

Bartle, R. (1996). Hearts, clubs, diamonds, spades: Players who suit MUDs. Journal of MUD research. [GS Search].

Basili, B., Caldiera, G., \& Rombach, H. (1994). Goal question metrics paradigm. Encyclopedia of software engineering. [GS Search].

Bateman, C., \& Boon, R. (2005). 21st century game design (game development series), charles river media. Inc., Rockland, MA. [GS Search].

Bateman, C., Lowenhaupt, R., \& Nacke, L. (2011). Player Typology in Theory and Practice. Proceedings of DiGRA 2011 Conference: Think Design Play., 1-24. [GS Search].

Borges, S., Reis, H, Durelli, V., Bittencourt, I., Jaques, P., \& Isotani, S. (2013). Gamificação aplicada à educação: um mapeamento sistemático. In Brazilian Symposium on Computers in Education (Simpósio Brasileiro de Informática na Educação-SBIE) (Vol. 24, No. 1, p. 234). doi: 10.5753/cbie.sbie.2013.234 [GS Search].

Borges, S., Durelli, V., Reis, H., \& Isotani, S. (2014). A systematic mapping on gamification applied to education. In Proceedings of the 29th annual acm symposium on applied computing (pp. 216-222). doi: 10.1145/2554850.2554956 [GS Search].

Bittencourt, I. \& Isotani, S. (2018). Evidence-based Computers in Education: A Manifesto (Informática na Educação baseada em Evidências: Um Manifesto). Brazilian Journal of Computers in Education (Revista Brasileira de Informática na Educação - RBIE), 26(3), 108-119. doi: 10.5753/RBIE.2018.26.03.108 [GS Search].

Briand, L. C., Differding, C. M., \& Rombach, H. D. (1996). Practical guidelines for measurement-based process improvement. Software Process Improvement and Practice, 2(4), 253-280. doi: 10.1002/(SICI)1099-1670(199612)2:4<253::AID-SPIP53>3.0.CO;2-G [GS Search]

Camilleri, V., Busuttil, L., \& Montebello, M. (2011). Social interactive learning in multiplayer games. In M. Ma, A. Oikonomou, \& L. C. Jain (Eds.), Serious games and edutainment applications (pp. 481-501). London: Springer London. doi: 10.1007/978-1-4471-2161$\underline{923}$ [GS Search]. 
Cermakova, L., Moneta, G. B., \& Spada, M. M. (2010). Dispositional flow as a mediator of the relationships between attentional control and approaches to studying during academic examination preparation. Educational Psychology, 30(5), 495-511. doi: $\underline{10.1080 / 01443411003777697 \text { [GS Search]. }}$.

Cheong, C., Cheong, F., \& Filippou, J. (2013). Quick quiz: A gamified approach for enhancing learning. In Pacis (p. 206). [GS Search].

Crust, L., \& Swann, C. (2013). The relationship between mental toughness and dispositional flow. European Journal of Sport Science, 13(2), 215-220. doi: 10.1080/17461391.2011.635698 [GS Search].

Csikszentmihalyi, M. (1975). Beyond boredom and anxiety. Jossey-Bass. [GS Search].

Csikszentmihalyi, M. (1991). Flow: The psychology of optimal experience. New York, NY: Harper Perennial. Paperback. [GS Search].

Deci, E. L., Koestner, R., \& Ryan, R. M. (1999). A meta-analytic review of experiments examining the effects of extrinsic rewards on intrinsic motivation. Psychological bulletin, 125(6), 627. doi: 10.1037/0033-2909.125.6.627 [GS Search].

Denny, P. (2013). The effect of virtual achievements on student engagement. In Proceedings of the sigchi conference on human factors in computing systems (pp. 763-772). doi: 10.1145/2470654.2470763 [GS Search].

Deterding, S., Sicart, M., Nacke, L., O’Hara, K., \& Dixon, D. (2011). Gamification. using game- design elements in non-gaming contexts. In Chi'11 extended abstracts on human factors in computing systems (pp. 2425-2428). doi: 10.1145/1979742.1979575 [GS Search].

D'Mello, S., Graesser, A., \& Picard, R. (2007). Toward an affect-sensitive autotutor. IEEE Intelligent Systems, 22(4), 53-61. doi: 10.1109/MIS.2007.79 [GS Search].

Domínguez, A., Saenz-de navarrete, J., Fernández-sanz, L., \& Pagés, C. (2013). Gamifying learning experiences: Practical implications and outcomes. Computers \& Education, 63, 380-392. doi: 10.1016/j.compedu.2012.12.020 [GS Search].

dos Santos W. O., Bittencourt, I. I., Dermeval, D., Isotani, S., Marques, L. B., \& Silveira, I. F. (2018). Flow Theory to Promote Learning in Educational Systems: Is it Really Relevant?. Brazilian Journal of Computers in Education, 26(2), 29-59. doi: 10.5753/RBIE.2018.26.02.29 [GS Search].

Eisenberger, R., Jones, J., Stinglhamber, F., Shanock, L., \& Randall, A. (2005). Flow experiences at work: For high need achievers alone? Journal of Organizational Behavior, 26(7), 755- 775. doi: 10.1002/job.337 [GS Search].

Faiola, A., Newlon, C., Pfaff, M., \& Smyslova, O. (2012). Correlating the effects of flow and telepresence in virtual worlds: Enhancing our understanding of user behavior in game-based learning. Computers in Human Behavior. doi: 10.1016/j.chb.2012.10.003 [GS Search].

Fritz, B. S., \& Avsec, A. (2007). The experience of flow and subjective well-being of music students. Horizons of Psychology, 16(2), 5-17. [GS Search].

Fu, F.-L., Su, R.-C., \& Yu, S.-C. (2009, jan). EGameFlow: A scale to measure learners' enjoyment of e-learning games. Computers \& Education, 52(1), 101-112. doi: 10.1016/j.compedu.2008.07.004 [GS Search]. 
Goehle, G. (2013). Gamification and web-based homework. Primus, 23(3), 234-246. doi: $\underline{10.1080 / 10511970.2012 .736451}$ [GS Search].

González-Cutre, D., Sicilia, Á., Moreno, J. A., \& Fernández-Balboa, J. M. (2009). Dispositional flow in physical education: Relationships with motivational climate, social goals, and perceived competence. Journal of Teaching in Physical Education, 28(4), 422-440. doi: 10.1123/itpe.28.4.422 [GS Search].

Gucciardi, D. F., Gordon, S., \& Dimmock, J. A. (2009). Evaluation of a mental toughness training program for youth-aged australian footballers: I. a quantitative analysis. Journal of applied sport psychology, 21(3), 307-323. doi: 10.1080/10413200903026066 [GS Search].

Hamari, J., \& Koivisto, J. (2014). Measuring flow in gamification: Dispositional Flow Scale-2. Computers in Human Behavior, 40(February 2016), 133-143. doi: 10.1016/j.chb.2014.07.048 [GS Search].

Hamari, J., Koivisto, J., \& Sarsa, H. (2014). Does gamification work? - A literature review of empirical studies on gamification. Proceedings of the Annual Hawaii International Conference on System Sciences, 3025-3034. doi: 10.1109/HICSS.2014.377 [GS Search].

Hamari, J., \& Tuunanen, J. (2014). Player Types: A Meta-synthesis. Transactions of the Digital Games Research Association, 1(2), 29-53. doi: 10.26503/todigra.v1i2.13 [GS Search].

Hanus, M., \& Fox, J. (2015). Assessing the effects of gamification in the classroom: A longitudinal study on intrinsic motivation, social comparison, satisfaction, effort, and academic performance. Computers and Education, 80, 152-161. doi: 10.1016/j.compedu.2014.08.019 [GS Search].

Hoffman, D. L., \& Novak, T. P. (1996). Marketing in Hypermedia Environmen Foundations: Conceptual Foundations. Journal of Marketing, 60(3), 50-68. doi: $\underline{10.1177 / 002224299606000304}$ [GS Search].

Huotari, K., \& Hamari, J. (2017). A definition for gamification: anchoring gamification in the service marketing literature. Electronic Markets, 27(1), 21-31. doi: 10.1007/s12525-015$\underline{0212-\mathrm{z}}$ [GS Search].

Jackson, S., \& Eklund, R. (2002). Assessing flow in physical activity: The Flow State Scale-2 and Dispositional Flow Scale-2. (Vol. 24) (No. 2). doi: 10.1123/jsep.24.2.133 [GS Search].

Jackson, S., \& Marsh, H. (1996). Development and validation of a scale to measure optimal experience: The Flow State Scale. Journal of Sport \& Exercise Psychology, 18, 17-35. doi: 10.1123/jsep.18.1.17 [GS Search].

Jackson, S., Martin, A. J., \& Eklund, R. C. (2008). Long and short measures of flow: the construct validity of the FSS-2, DFS-2, and new brief counterparts. Journal of sport \& exercise psychology, 30(5), 561-587. doi: 10.1123/jsep.30.5.561 [GS Search].

Kapp, K. M. (2012). The gamification of learning and instruction: game-based methods and strategies for training and education. John Wiley \& Sons. [GS Search].

Kiili, K., De Freitas, S., Arnab, S., \& Lainema, T. (2012). The design principles for flow experience in educational games. Procedia Computer Science, 15, 78-91. doi: 10.1016/j.procs.2012.10.060 [GS Search].

Landers, R. N., \& Callan, R. C. (2011). Casual social games as serious games: The psychology of gamification in undergraduate education and employee training. In Serious games and 
edutainment applications (pp. 399-423). Springer. doi: 10.1007/978-1-4471-2161-9 20 [GS Search].

Levy, Y. (2007). Comparing dropouts and persistence in e-learning courses. Computers \& Education, 48(2), 185 - 204. doi: 10.1016/j.compedu.2004.12.004 [GS Search].

Masthoff, J., \& Vassileva, J. (2015). Tutorial on Personalization for Behaviour Change. Proceedings of the 20th International Conference on Intelligent User Interfaces - IUI '15, 2015-Janua(March), 439-442. doi: 10.1145/2678025.2716264 [GS Search].

Monterrat, B., Desmarais, M., \& Lavou, E. (2015). A player model for adaptive gamification in learning environments. In International conference on artificial intelligence in education (pp. 297-306). doi: 10.1007/978-3-319-19773-9_30 [GS Search].

Murcia, J. A. M., Gimeno, E. C., \& Coll, D. G. C. (2008). Relationships among goal orientations, motivational climate and flow in adolescent athletes: Differences by gender. The Spanish journal of psychology, 11(1), 181-191. doi: 10.1017/S1138741600004224 [GS Search].

Nacke, L., Bateman, C., \& Mandryk, R. (2011). BrainHex: Preliminary results from a neurobiological gamer typology survey. Lecture Notes in Computer Science (including subseries Lecture Notes in Artificial Intelligence and Lecture Notes in Bioinformatics), 6972 LNCS, 288-293. doi: 10.1007/978-3-642-24500-8 31 [GS Search].

Nacke, L., Bateman, C., \& Mandryk, R. (2014). BrainHex: A neurobiological gamer typology survey. Entertainment Computing, 5(1), 55-62. doi: 10.1016/j.entcom.2013.06.002 [GS Search].

Orji, R. (2014). Design for behaviour change: a model-driven approach for tailoring persuasive technologies (Unpublished doctoral dissertation). University of Saskatchewan. doi: 10388/ETD-2014-06-1555 [GS Search].

Pavlas, D., Heyne, K., Bedwell, W., Lazzara, E., \& Salas, E. (2010). Game-based Learning: The Impact of Flow State and Videogame Self-efficacy. Proceedings of the Human Factors and Ergonomics Society Annual Meeting, 54, 2398-2402. doi: 10.1177/154193121005402808 [GS Search].

Prensky, M. (2003). Digital game-based learning. Computers in Entertainment (CIE), 1(1), 2121. doi: $\underline{10.1145 / 950566.950596}$ [GS Search].

Procci, K., Singer, A. R., Levy, K. R., \& Bowers, C. (2012). Measuring the flow experience of gamers: An evaluation of the DFS-2. Computers in Human Behavior, 28(6), 2306-2312. doi: 10.1016/j.chb.2012.06.039 [GS Search].

Ritchie, J., \& Spencer, L. (2002). Qualitative data analysis for applied policy research. The qualitative researcher's companion, 573(2002), 305-329. [GS Search].

Salanova, M., Rodríguez-Sánchez, A. M., Schaufeli, W. B., \& Cifre, E. (2014). Flowing together: a longitudinal study of collective efficacy and collective flow among workgroups. The Journal of psychology, 148(4), 435-455. doi: 10.1080/00223980.2013.806290 [GS Search].

Sheldon, L. (2011). The multiplayer classroom: Designing coursework as a game. Cengage Learning. [GS Search]. 
Sinnamon, S., Moran, A., \& O'Connell, M. (2012). Flow among musicians: Measuring peak experiences of student performers. Journal of Research in Music Education, 60(1), 6-25. doi: 10.1177/0022429411434931 [GS Search].

Solingen, R., \& Berghout, E. (1999). The goal/question/metric method: A practical guide for quality improvement of software development. McGraw-Hill. [GS Search].

Wang, C. K. J., Liu, W. C., \& Khoo, A. (2009, Sep 01). The psychometric properties of dispositional flow scale-2 in internet gaming. Current Psychology, 28(3), 194-201. doi: 10.1007/s12144-009-9058-x [GS Search].

Weibel, D., Wissmath, B., Habegger, S., Steiner, Y., \& Groner, R. (2008). Playing online games against computer- vs. human-controlled opponents: Effects on presence, flow, and enjoyment. Computers in Human Behavior, 24(5), 2274-2291. doi: 10.1016/j.chb.2007.11.002 [GS Search].

Werbach, K. (2014). (re)defining gamification: A process approach. In Persuasive technology: 9th international conference, persuasive 2014, padua, italy, may 21-23, 2014. proceedings (pp. 266-272). Cham: Springer International Publishing. doi: 10.1007/978-3-319-07127523 [GS Search].

Werbach, K., \& Hunter, D. (2012). For the win: How game thinking can revolutionize your business. Wharton Digital Press. [GS Search].

Wohlin, C., Runeson, P., Höst, M., Ohlsson, M. C., Regnell, B., \& Wesslén, A. (2012). Experimentation in software engineering. Springer Science \& Business Media. [GS Search].

Wu, W., \& Chen, L. (2015). Implicit acquisition of user personality for augmenting movie recommendations. In F. Ricci, K. Bontcheva, O. Conlan, \& S. Lawless (Eds.), User modeling, adaptation and personalization: 23rd international conference, umap 2015, dublin, ireland, june 29 -july 3, 2015. proceedings (pp. 302-314). Cham: Springer International Publishing. doi: 10.1007/978-3-319-20267-9 25 [GS Search].

Yee, N. (2006). Motivations for Play in Online Games. CyberPsychology \& Behavior, 9(6), 772-775. doi: 10.1089/cpb.2006.9.772 [GS Search].

Yee, N., Ducheneaut, N., \& Nelson, L. (2012). Online gaming motivations scale: development and validation. Proceedings of the 2012 ACM annual conference on Human Factors in Computing Systems - CHI '12, 2803. doi: 10.1145/2207676.2208681 [GS Search].

\section{Appendix}

\section{Flow Questionnaire}

Name:

Date:

FOR EACH ASSERT BELOW, FILL INTO A SCALE OF 1 TO 5, YOUR OPINION REGARDING THE GAME. LEGEND: 1 TO FULLY DISAGREE, 2 TO PARTIALLY DISAGREE, 3 TO NEUTER, 4 TO PARTIALLY AGREE AND 5 TO FULLY AGREE.

\begin{tabular}{|l|l|l|l|l|l|l|}
\hline & Assert & 1 & 2 & 3 & 4 & 5 \\
\hline 01 & I am challenged, but I believe my skills allow me to meet the challenge. & & & & \\
\hline 02 & I make the correct movements without thinking about trying to do so. & & & & \\
\hline 03 & I know clearly what I want to do. & & & & \\
\hline
\end{tabular}




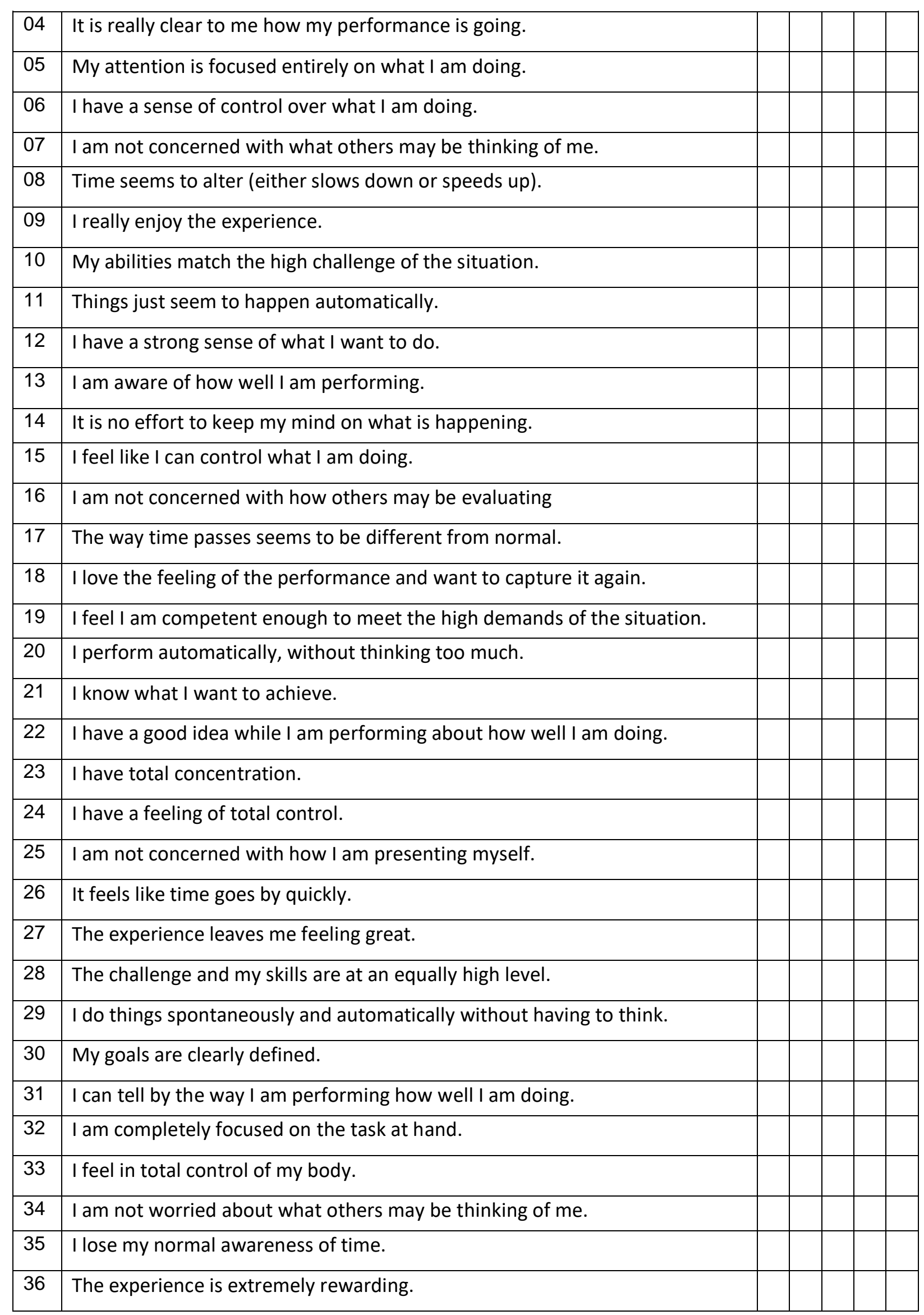




\section{Bartle test}

Name:

Sex: $(\quad)$ Male $(\quad)$ Female

This questionnaire aims to find out what your player profile is by simulating a situation on a virtual platform and does not configure itself to real-life situations.

\section{Do you like games? ( ) Yes ( ) No}

\section{Which is more enjoyable to you?}

) Killing a big monster

) Bragging about it to your friends?

\section{Which do you enjoy more in MUD quests?}

( ) Getting involved in the storyline

( ) Getting the rewards at the end?

\section{Would you rather be:}

) Popular

) Wealthy

\section{Which do you enjoy more on a MUD?:}

( ) Getting the latest gossip

( ) Getting a new item

\section{Which would you rather have, as a player on a MUD?}

( ) A private channel, over which you and your friends can communicate

( ) Your own house, worth millions of gold coins

\section{Which would you enjoy more as a MUD player?}

) Running your own tavern?

) Making your own maps of the world, then selling them?

\section{What's more important in a MUD to you?}

) The number of people

) The number of areas to explore

\section{What's more important to you?}

) The quality of roleplaying in a mud

) The uniqueness of the features, and game mechanic 


\section{You are being chased by a monster on a MUD. Do you?}

( ) Ask a friend for help in killing it

( ) Hide somewhere you know the monster won't follow

10. You're a player on a mud, and about to go into an unknown dungeon. You have your choice of one more person for your party:

( ) A bard, who's a good friend of yours and who's great for entertaining you and your friends

( ) A wizard, to identify the items that you find there

\section{Would you rather:}

) Vanquish your enemies

) Convince your enemies to work for you, not against you

\section{Which is more exciting?}

) A well-roleplayed scenario

) A deadly battle

\section{Which would you enjoy more?}

) Winning a duel with another player

) Getting accepted by a clan

\section{What's worse:}

) To be without power

) To be without friends

\section{Would you rather}
) Hear what someone has to say
) Show them the sharp blade of your axe

16. On a MUD, a new area opens up. Which do you look forward to more?

) Exploring the new area, and finding out its history

) Being the first to get the new equipment from the area

\section{On a MUD, would you rather be known as:}

) Someone who can run from any two points in the world, and really knows their way around.

) The person with the best, most unique equipment in the game

18. Would you rather: 


\section{) Become a hero faster than your friends? \\ ) Know more secrets than your friends?}

\section{Do you tend to:}

) Know things no one else does

) Have items no one else does

20. Which would you rather do:

) Solve a riddle no one else has gotten

) Getting to a certain experience level faster than anyone else

\section{On a MUD, would rather be known for:}

) Knowledge

) Power

22. Would you rather:

) Defeat an enemy

) Explore a new area

23. If you're alone in an area, do you think:
) It's safe to explore
) You'll have to look elsewhere for prey

24. You learn that another player is planning your demise. Do you:

) Go to an area your opponent is unfamiliar with and prepare there

) Attack him before he attacks you

25. You meet a new player. Do you think of him as:

) Someone who can appreciate your knowledge of the game

) As potential prey

26. On a mud, would you rather:

) Have a sword twice as powerful as any other in the game

) Be the most feared person in the game

27. On a mud, would you be more prone to brag about:

) How may other players you've killed

) Your equipment 
28. Would you rather have:

) A spell to damage other players

) A spell that increases the rate at which you gain experience points?

29. Would you rather receive as a quest reward:

( ) Experience points

( ) A wand with 3 charges of a spell that lets you control other players, against their will.

30. When playing a video game, is it more fun to:

) Have the highest score on the list?

) Beat your best friend one-on-one? 